F. Barth

B. Baum

D. Bremen

T. Meuser

W. H. Jost

\title{
Die indirekten Kosten des idiopathischen Parkinson-Syndroms
}

Indirect Costs in Idiopathic Parkinson's Disease

F. Barth, B. Baum, D. Bremen, T. Meuser, W. H. Jost Die indirekten Kosten des idiopathische Parkinson-Syndroms Fortschritte der Neurologie, Psychiatrie: E-first-Publikation vom 15. November 2004

Auf Seite 2, 3. Absatz, 4. Zeile muss es heißen: Anhand der vorliegenden prospektiven Studie über die im Zusammenhang mit M. Parkinson anfallenden Kosten lässt sich die Thematik der indirekten Kosten verdeutlichen.

Die Arbeit ist im Druck erschienen: 2005; 73: 187 - 191. 